\title{
ETHNOLOGY
}

Copyright (C 2018 by the Kalmyk Scientific Center of the Russian Academy of Sciences

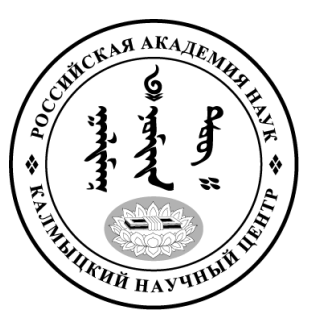

Published in the Russian Federation

Oriental Studies (Previous Name: Bulletin of the Kalmyk Institute for

Humanities of the Russian Academy of Sciences)

Has been issued as a journal since 2008

ISSN: 2619-0990; E-ISSN: 2619-1008

Vol. 38, Is. 4, pp. 43-51, 2018

DOI 10.22162/2619-0990-2018-38-4-43-51

Journal homepage: https://kigiran.elpub.ru

УДК 294.321

\section{Буддисты-миряне: \\ проблемы классификации и подходы к изучению}

Рустам Тагирович Сабиров ${ }^{1}$

${ }^{1}$ кандидат исторических наук, доцент, Институт стран Азии и Африки, МГУ им. М. В. Ломоносова (125009, Россия, г. Москва, ул. Моховая, д. 11, стр. 1). ORCID: 0000-0003-4660-098. E-mail: tabarzin@gmail.com

Аннотация. В XX в. буддисты-миряне начали играть гораздо более важную роль в религиозных процессах на Западе и в странах Азии. Попытки категоризации буддистов на Западе показали, что привычное разделение на монахов и мирян не работает. Выходя за пределы Азии и адаптируясь к новым социально-политическим, экономическим и культурным условиям, буддизм трансформируется и неизбежно обретает новые формы. Выработанные за многие годы изучения буддизма в Азии подходы и критерии не описывают всего многообразия форм вовлеченности западных последователей. Да и в самих странах Азии в результате процессов модернизации, секуляризации и глобализации происходят серьезные трансформации буддийских сообществ. В статье показаны основные подходы к классификации современных буддистов и те теоретические проблемы, с которыми сталкиваются ученые при этом. На примере изучения последователей Оле Нидала выяснилось, что определение аутентичности тех или иных буддийских групп и оценка их деятельности нередко зависит от религиозной принадлежности самих исследователей. Описание таких групп как «необуддийских» никак не раскрывает их сути.

В настоящее время проблема классификации буддистов-мирян лучше всего разработана на североамериканском материале. Ученые подвергают критике нормативный подход, согласно которому религиозная идентичность - это нечто цельное и фиксированное. Напротив, идентичность современных западных буддистов - результат множества влияний. Формальные критерии - принятие прибежища, посещение храмов и т. п. - не позволяют выявить все многообразие последователей буддизма. Западные исследователи предлагают обратить внимание на многочисленную группу людей, которые формально не принадлежат буддизму, но проявляют к нему интерес - их называют «сочувствующими» (sympathizers). Они являются важной частью истории буддизма примерно с конца XIX в. Ученые признают допустимым и важным самый простой критерий - буддистом может считаться тот, кто называет себя таковым.

Основные тренды в трансформации буддийской практики на Западе: отсутствие четкой грани между мирянами и «профессиональными буддистами», отсутствие единых авторитетов, умаление роли монашества, эгалитаризм, увеличение роли женщин, активное участие в общественной жизни, нередко акцентирование психологической, а не религиозной природы буддийской практики. Некоторые исследователи предлагают называть это новым буддизмом - качественно иным явлением, порожденным в результате адаптации буддизма к обществу постмодерна.

Популярная концепция «двух буддизмов», выделяющая этнических буддистов (иммигрантов) и конвертитов («белых буддистов») в последнее время подвергается критике. Использова- 
ние этой концепции в долгосрочной перспективе вызывает проблемы: как классифицировать потомков иммигрантов и конвертитов? В качестве альтернативы некоторые ученые предлагают говорить о традиционном и модернистском буддизме. Однако этот подход не учитывает, что не все конвертиты следуют модернистскому буддизму, и не все иммигранты - традиционному.

Проблема классификации буддистов актуальна не только в западном контексте. В статье на примере исследований буддизма в Монголии и Бурятии показано, что там также присутствует эклектизм и сложно выделить четкие категории верующих.

Ключевые слова: буддизм, буддизм на Западе, миряне, буддология

Буддийские институты в XX в. претерпели значительные изменения, связанные с наследием колониализма, процессами национального возрождения, миграциями, последствиями секуляризации и модернизации. Буддизм вышел за пределы Азии: стали появляться буддийские общины на Западе, состоящие как из выходцев из Азии, так и западных последователей Будды.

Если в рамках традиционных обществ статусы буддистов были более-менее четко очерчены - монахи, миряне, миряне-практики, то в современных обществах появилось гораздо больше форм и проявлений приверженности буддизму. При этом ученые обратили внимание на эти группы не так давно, прежде занимаясь изучением буддийских текстов, монастырей, роли буддизма в политике и т. п.

Цель данной статьи - охарактеризовать основные проблемы, возникающие при изучении буддистов-мирян, и показать основные подходы к их решению, выработанные в современной историографии. Статья не претендует на всеохватность, в ней рассматриваются, прежде всего, основные работы и концепции.

\section{Буддисты-миряне согласно канону}

Согласно большинству классических работ по буддизму, буддийское общество состоит из монахов (бхиккху), монахинь (бхиккхуни) и мирян: мужчин (упасака) и женщин (упасика). Миряне обеспечивают монахов и монахинь одеждой, едой, дают кров и ведут праведный образ жизни, соблюдая пять мирских обетов. При этом они не способны достичь духовного уровня монахов в этой жизни. Они могут только накапливать заслуги для благого перерождения, чтобы в будущей жизни принять монашество. Оливер Фрайбергер (Oliver Freiberger) оспаривает эту точку зрения, говоря, что в палийском каноне можно встретить пассажи, в которых миряне контролируют поведение монахов и демонстрируют высокий уровень духовного постижения, получают наставления, касающиеся сложных аспектов буддийского учения, и испытывают сильные медитативные состояния [Freiberger 2004: 272].

Исходя из этого, не совсем верно утверждать, что современные формы буддийской практики и духовной жизни, в том числе увеличение роли мирян, не имеют аналогов в истории буддизма. Однако, в отличие от своих предшественников, современные миряне не так заинтересованы в накоплении заслуг и рождении в буддийских небесах, они предпочитают медитацию [Freiberger 2004: 280]. По мнению О. Фрайбергера, подобный интерес отчасти сформирован предыдущими поколениями ученых, которые в своих трудах выделяли именно эти темы, а не другие [Freiberger 2004: 281].

Вместе с тем, даже учитывая более высокую роль мирян в истории буддизма, чем было принято ранее думать, именно модернизация буддийских обществ в XX в. привела к серьезным, качественным переменам. Повышение грамотности дало мирянам возможность самостоятельно изучать и толковать тексты и соответственно обрести большую независимость от монахов [Hardacre 2004: 448]. Кроме того, как будет показано ниже, сам статус мирянина не описывает многообразия типов буддистов в современном мире.

\section{Проблема аутентичности школ и нейтральности исследователей}

Проникая на Запад, традиционные буддийские институты неизбежно трансформируются в новых условиях. Кроме того, на Западе под влиянием буддийских идей и представлений могут возникать какие-то свои новые формы. На российском материале этот вопрос исследовала Е. П. Островская, которая вообще одной из первых среди российских исследователей занялась изучением буддистов-мирян. Она изучала общины последователей карма кагью - 
учеников Оле Нидала; дзогчен-общину учеников Намкая Норбу и религиозную группу Римей под руководством Виталия Федько [Островская 2016].

Согласно Е. А. Островской, несмотря на заявления Оле Нидала, Намкая Норбу и лидера общины Римей о прямой связи их сообществ с соответствующими тибетскими направлениями, наблюдаемые в них формы религиозной жизни качественно отличны от тибетских прототипов [Островская 2016: 186]. В отличие от традиционных тибетских лам, Нидал и Норбу не входят в иерархию школьных религиозных статусов, создают автобиографии, чтобы легитимизировать свой статус на Западе, предлагают собственное видение буддийской организации, проповеди и т. п. [Островская 2016: 187]. Они не соотносят свою деятельность с традиционным буддийским календарем, Нидал проводит ритуал пхова без специальных посвящений и т. п. [Островская 2016: 188-189].

С. И. Шатравский касается схожих проблем на материале белорусских общин последователей бон, дзогчен-общины и карма кагью [Шатравский 2018]. Совершенно справедливо он отмечает, что порой проблема классификации сообществ европейцевконвертитов решается механически - путем прибавления приставки «нео» или «не» (необуддизм, нетрадиционная религия) [Шатравский 2018: 143]. Подобный подход ничего не объясняет и никак не выявляет суть изучаемого феномена. Более того, некоторые религиоведы (например, Л. И. Григорьева, Е. Г. Балагушкин) идут еще более простым путем, причисляя нетрадиционные для России или Беларуси религиозные группы к сектам и культам [Шатравский 2018: 158]. Некоторые видные востоковеды (Н. Л. Жуковская, Е. А. Торчинов), напротив, обосновывают традиционность этих школ [Шатравский 2018: 158].

Интересно сравнить позицию

Е. А. Островской и некоторых религиоведов, касающуюся буддизма Алмазного Пути Оле Нидала, с работами Буркхардта Шереpa (Burkhard Scherer), профессора Школы гуманитарных наук Университета ЧёрчКрайст в Кентербери (Великобритания). Он отмечает, что одно из самых массовых и активных буддийских сообществ на Западе буддизм Алмазного пути карма кагью остается малоизученным, поскольку многие исследователи руководствуются личными предпочтениями и установками. Среди западных буддологов и тибетологов много последователей школы гелуг, поэтому они с пренебрежением относятся к деятельности Оле Нидала, указывая на несоответствия его видения буддизма традиционным направлениям буддизма [Scherer 2009: 28].

Организации, связанные с гелуг, поддерживают научные мероприятия и крупные издательства буддийской литературы, также влияя на ситуацию. Видимо, столкнувшись с этой проблемой, последователи карма кагью сами начали заниматься научными исследованиями. В России Ассоциация буддистов Алмазного Пути активно сотрудничает с буддологами и востоковедами, организует научные конференции и мероприятия [Научно-практические конференции]. Б. Шерер также является последователем карма-кагью и вице-президентом Международного форума буддистов мирян (International Lay Buddhist Forum).

Б. Шерер показывает, что деятельность Оле Нидала вполне соответствует парадигме тибетского буддизма: ученичество у 16го Кармапы, связь с линией махасиддхов, подтвержденная авторитетным тибетским ламой Лопоном Цечу Ринпоче (1918-2003) [Scherer 2009: 33]. Будучи мирянином, Оле Нидал не нуждается в монастырском образовании [Scherer 2009: 35], а практики, которые он дает, - гуру-йога (медитация на Кармапу), пуджи, пхова, нёндро (предварительные практики) - являются традиционными буддийскими практиками [Scherer 2009: 36; Scherer 2014].

Здесь возникает любопытная ситуация, когда ученые - последователи разных направлений буддизма - фактически ведут дискуссию на страницах научных журналов. Конечно, возникает вопрос о том, насколько непредвзяты выводы такого ученого, но репутация журналов и аргументированность выводов позволяют относиться к таким работам серьезно.

Следует отметить, что проблема классификации такого рода общин и их последователей также зависит не только от законодательства страны или выводов экспертов, но и устройства самих этих организаций. Интересным в этом смысле представляется пример корейского буддийского ордена Чогье, где в 1995 г. ввели регистрацию последователей-мирян, которым выдают соответствующие удостоверения [Kaplan 2017: 144-145]. А в 2001 г. каждого мирянина 
обязали проходить образовательный курс по буддизму из 12 лекций, прежде чем он сможет стать легитимным последователем этого ордена [Kaplan 2017: 145].

\section{Религиозная идентичность как трудноопределимое понятие}

Проблема классификации и идентификации буддистов-мирян на Западе, пожалуй, лучше всего на данный момент разработана на североамериканском материале. Предлагается даже выделить североамериканских буддистов в качестве отдельной области исследований в рамках буддологии. Пол Дэвид Нумрич (Paul David Numrich), проанализировав критерии, позволяющие такого рода обособление, - наличие специализации (т. е. подготовка ученых, теории, терминология и методы), организаций (профессиональные ассоциации, регулярные встречи и конференции, академические программы и факультеты), публикаций приходит к заключению, что изучение буддистов в Северной Америке представляет на данный момент «прото-область» ${ }^{1}$ исследований [Numrich 2008: 8].

Одной из основных работ здесь можно назвать коллективную монографию «Дхарма на Запад. Буддизм за пределами Азии» под редакцией известных специалистов по теме - Чарльза Пребиша и Мартина Баумана [Westward Dharma 2002]. В первой главе Томас Твид (Thomas A. Tweed) подвергает справедливой критике устоявшийся нормативный подход, согласно которому религиозная идентичность - это нечто цельное и фиксированное и всех можно разделить на две категории - последователи (adherents) и «посторонние» (non-adherents) [Westward Dharma 2002: 17]. Последователь - это тот, кто разделяет определенные верования и практики, принадлежит определенной религиозной организации или участвует в ее обрядах и ритуалах [Westward Dharma 2002: 18]. Как пишет Т. Твид, такой стандартизированный подход проблематичен с концептуальной точки зрения и упускает важные вещи; он предполагает, что религия - это статичное, изолированное и унифицированное явление, не подверженное внешним влияниям [Westward Dharma 2002: 18].

Чарльз Пребиш, один из пионеров изучения буддизма в Америке, также отмечает,

1 Здесь и далее термины и понятия даются в авторском переводе. что традиционные способы идентификации буддистов в Азии - принятие прибежища и пяти мирских обетов - не адекватны для анализа американских буддистов, чья идентичность - результат множества влияний [Storhoff, Whalen-Bridge 2010: 151-154; Prebish 1979: 43-44].

Более продуктивным и корректным будет признание того факта, что религиозная идентичность - сложное явление, выходящее за рамки простых критериев. Человек может посещать различные храмы и участвовать в ритуалах разных религий, как, например, в Японии (буддизм и синто) или в Бурятии (буддизм и шаманизм). В случае с конвертитами, переходя из одной религии в другую, прежние представления и верования редко утрачиваются полностью [Westward Dharma 2002: 19]. Джанет Maклилан (Janet Mclellan) также считает такое разделение слишком упрощающим и редукционистским, не отражающим всего многообразия контекстов, верований, практик и форм участия [Numrich 2008: 22].

\section{Сочувствующие и новый буддизм}

Чтобы нагляднее проиллюстрировать свою позицию и показать, в чем неэффективность нормативного подхода, Т. Твид предлагает обратить внимание на многочисленную группу людей, которые формально не принадлежат буддизму, но проявляют к нему интерес. Он называет их «сочувствующими» (sympathizers) или, если перевести дословно», «буддистами прикроватной тумбочки» (night-stand Buddhists), потому что на этой тумбочке у них лежит книга по буддизму, которую они читают перед сном, и так, собственно, выражается их причастность к буддизму [Westward Dharma 2002: 20]. Согласно ряду опросов, в Европе и Америке миллионы людей проявляют интерес и симпатии к буддизму, говорят, что эта религия серьезно на них повлияла, время от времени посещают занятия по медитации, лекции, участвуют в буддийских форумах и группах в социальных сетях, украшают комнату предметами «в буддийском стиле», но они не считают себя буддистами. Однако, как пишет Т. Твид, эти сочувствующие являются важной частью истории буддизма примерно с конца XIX в. [Westward Dharma 2002: 21].

Помимо стандартных критериев определения принадлежности человека к буд- 
дизму (принятие прибежища, наличие учителя, посещение храмов), Твид признает допустимым и важным самый простой критерий - буддистом может считаться тот, кто называет себя таковым [Westward Dharma 2002: 24]. Конечно, это создает ряд проблем, поскольку буддистами себя могут называть последователи Е. П. Блаватской и каких-то маргинальных учений, имеющие крайне опосредованное отношение к буддизму. Исследователю здесь приходится делать непростой выбор и, видимо, использовать дополнительные критерии, но это оправдано, поскольку позволяет не упустить важные группы и тенденции, связанные с буддизмом на Западе. Ч. Пребиш разделяет подобную точку зрения и тоже предлагает считать буддистом того, кто сам себя называет буддистом [Storhoff, WhalenBridge 2010: 155].

Известный буддийский наставник и буддолог Алан Уоллес (B. Alan Wallace) предлагает свою классификацию верующих, основанную на буддийской практике. Он выделяет три группы западных практиков буддизма: 1) участники буддийских учений, ретритов, медитаций и т. п.; 2) ученики буддийских наставников; 3) те, кто сами причисляют себя к буддизму и называют себя буддистами. При этом в первые две группы могут входить католики, иудеи, психологи и другие люди - как религиозные, так и нерелигиозные, сочетающие в своей жизни буддийские идеи и практики с представлениями из других религий и учений [Westward Dharma 2002: 34-35]. Принимая во внимание подобную эклектичность буддизма, ученый задается вопросом: насколько вообще корректно рассматривать буддизм исключительно как религию, будь то на Западе или в Азии? [Westward Dharma 2002: 35 .

С точки зрения практики, буддизм на Западе многими последователями не рассматривается как религия, а в странах Азии буддизм включает такие практики, как предсказание будущего, гадания, похоронные обряды, умилостивление божеств и духов, которые не находят подкрепления в буддийском каноне [Westward Dharma 2002: 35]. Возможно, более продуктивным в этом смысле может быть использование разделения на религию и духовность (spirituality) или «духовный поиск» ${ }^{1}$ [Numrich 2008: 24].

\footnotetext{
${ }^{1}$ Перевод автора.
}

Многие западные буддисты отрицают концепцию перерождений в низших мирах (адах) в результате неблагих поступков, поскольку это слишком напоминает им христианство; не разделяют представление о карме и продолжении потока сознания после смерти [Westward Dharma 2002: 46]. Это, кстати, подкрепляет тезис Т. Твида о несовершенстве формальных критериев определения принадлежности к буддизму. А. Уоллес выделяет основные тренды в трансформации буддийской практики на Западе: отсутствие четкой грани между мирянами и «профессиональными буддистами», отсутствие единых авторитетов, умаление роли монашества, эгалитаризм, увеличение роли женщин, активное участие в общественной жизни, нередко акцентирование психологической, а не религиозной природы буддийской практики [Westward Dharma 2002: 35].

Джеймс Уильям Коулман (James William Coleman) предлагает называть буддизм, ориентированный на медитацию и представленный преимущественно западными последователями, «новым буддизмом», поскольку это - принципиально иная форма буддизма, приспособившаяся к социальным условиям общества постмодерна [Numrich 2008: 185]. Для «нового буддизма» характерна более зыбкая грань между религиозным специалистом и мирянином, но и тот, и другой стремятся к освобождению, используя медитацию и другие подобные методы [Numrich 2008: 188].

Западные последователи представляют собой новый тип буддистов, не имеющий, по мнению Дж. У. Коулмана, аналогов в азиатских обществах. Не будучи монахами, они проводят большую часть времени в своих центрах, уделяя почти все время и силы на достижение своих буддийских идеалов. Некоторые из них принимают монашеские обеты, но не пользуются таким уважением и почетом, как монахи в странах Азии. Cреди других важных особенностей нового западного буддизма - переосмысление роли женщин и эклектизм [Numrich 2008: 190].

Действительно, буддисты на Западе оказались в уникальной ситуации - впервые за 2500-летнюю историю буддизма одновременно в едином пространстве сосуществуют не только различные религии, учения и наука, но и разные школы и направления буддизма, которые подпитывают друг друга и позволяют заимствовать свои идеи и прак- 
тики. Последователи одной традиции могут посещать центры другой, слушать лекции других наставников и, конечно, читать книги самых разных авторов. В подтверждение своего тезиса Дж У. Коулман приводит пример известных буддийских наставников на Западе, которые в конце концов сформировали свои собственные традиции и концепты: Сюнрю Судзуки и его «сознание начинающего», Чогьям Трунгпа и «безумная мудрость», Джек Корнфилд с попытками соединить буддизм и психологию [Numrich 2008: 190].

\section{Два буддизма}

Еще один вид классификации современных буддистов исходит из концепции «двух буддизмов», предложенной Чарльзом Пребишем в 1979 г., и предполагает разделение на этнических буддистов (иммигрантов) и конвертитов («белых буддистов») [Prebish 1979]. Эти две группы по-разному видят цели и задачи буддийской практики [Numrich 2003: 55].

С критикой данной концепции выступает Мартин Бауман (Martin Baumann), по мнению которого нужно смотреть не столько на происхождение верующего, сколько на то, к какому направлению буддизма он принадлежит - традиционному или модернистскому [Westward Dharma 2002: 52].

Основная проблема концепции «двух буддизмов» заключается в том, что она позволяет более-менее точно классифицировать буддистов в первом поколении, а дальше начинаются сложности. Если мы причисляем иммигранта к представителям этнического буддизма, то как быть с его детьми и внуками? [Westward Dharma 2002: 53]. Точно так же потомки буддиста-конвертита будут, согласно этой классификации, конвертитами при отсутствии самого факта обращения [Westward Dharma 2002: 54]. Вместо этого разделение на традиционный буддизм, основанный на вере и ритуалах, и модернистский - c акцентом на медитации, изучении текстов и рационализме, по мнению М. Баумана, решает эту проблему, в то же время адекватно описывая и этнических буддистов, и конвертитов [Westward Dharma 2002: 58]. Другое дело, что эта традиционно-модернистская дихотомия также не всегда отражает все многообразие буддийского опыта. Так, далеко не все конвертиты следуют модернистским версиям буддизма, а этнические буддисты порой отвергают или критикуют обряд- ность и суеверия традиционного буддизма [Numrich 2008: 25].

Ч. Пребиш считает более продуктивным не разделять буддистов по этническому признаку и не выделять «два буддизма», а сосредоточиться на той функции, которую играет буддизм в их жизни [Storhoff, Whalen-Bridge 2010: 157]. Например, в сообществах азиатов-иммигрантов буддизм выполняет интегрирующую функцию, давая им чувство принадлежности к своей группе, историческому и культурному наследию. А конвертитам предлагает альтернативную религиозную идентичность и иную картину мира [Storhoff, Whalen-Bridge 2010: 157]. Также он пишет, что важно понимать, как именно та или иная разновидность буддизма пришла из Азии в Америку. Он выделяет три линии передачи буддизма из Азии. Во-первых, буддизм может быть «импортирован», это означает, что новая культура или страна нуждаются в этой традиции [Storhoff, Whalen-Bridge 2010: 157]. Его также можно назвать «элитным», поскольку люди сталкиваются с ним в ходе путешествия или обучения и, соответственно, имеют достаточно средств и времени на это, то есть принадлежат к элите [Storhoff, WhalenBridge 2010: 157]. К «импортированному» буддизму исследователь относит, прежде всего, тибетский буддизм, дзэн и випассану. Во-вторых, есть «экспортный» буддизм, что отражает желание последователей в Азии познакомить со своей традицией жителей других стран и регионов. Поскольку это предполагает миссионерскую деятельность, его также можно назвать «евангелическим» буддизмом [Storhoff, Whalen-Bridge 2010: 158]. Наиболее яркий пример - Сока Гаккай. И, наконец, этнический буддизм, который попадает на Запад вместе с его носителями-иммигрантами [Storhoff, WhalenBridge 2010: 158].

\section{Буддисты-миряне в азиатском контексте}

Известный монголовед Йохан Эльверског попытался использовать концепцию «двух буддизмов» для анализа буддизма в современной Монголии, где к «этническим» буддистам он относит монголов, заинтересованных только в ритуально-обрядовой стороне буддизма, а к «конвертитам» - последователей дхарма-центров, основанных транснациональными организациями [Elverskog 2006: 29-46]. По сути, Й. Эльвер- 
ског выделяет традиционный и модернистский буддизм, и категоризация М. Баумана подошла бы ему больше. Он пишет, что в Монголии между двумя этими группами нет барьеров - и та, и другая взаимодействуют в процессе создания «монгольского буддизма» [Elverskog 2006: 46].

Антрополог Абрамс-Кавуненко, изучавшая монгольских буддистов-мирян в Улан-Баторе, также отмечает зыбкость границ и эклектичность буддизма в Монголии [Abrahms-Kavunenko 2012: 279-297]. Религиозные идеи и практики здесь заимствуются из многочисленных и разнообразных источников как внутри страны, так и извне [Abrahms-Kavunenko 2012: 282]. Выделить какие-то четкие категории монгольских буддистов представляется сложным, поскольку их знания и опыт формируются на основе разрозненных и зачастую неполных данных о буддизме, а возникающие в результате этого пробелы заполняются какими-то альтернативными религиозными дискурсами. Этому способствует и стремительно меняющаяся городская среда, в которой постоянно возникают новые идеи и практики [Abrahms-Kavunenko 2012: 283].

С. Г. Жамбалова, изучавшая народный буддизм (она проводит аналогию с «народным православием») в современной Бурятии, выделяет три группы последователей, беря в качестве критериев этничность, религиозную самоидентификацию и практику [Жамбалова 2014: 116]. Для первых двух групп характерна «нечёткость ... религиозных дефиниций», недостаточное знание основ буддизма [Жамбалова 2014: 116]. А вот третья группа - практикующие буддисты, в данном случае - пожилые женщины, участвующие в обряде сангарил (собрания с чтением молитв), заметно выделяются на фоне первых двух [Жамбалова 2011: 87-93].

Т. Б. Бадмацыренов, также основываясь на религиозных практиках современных бурят, выделяет два основных типа буддистов-мирян: прихожан, то есть «местные территориальные сообщества верующих», и членов общин, возникших вокруг известных буддийских наставников, таких как геше Джампа Тинлей, Еше Лодой ринпоче, Оле Нидал, Намкай Норбу и др. [Бадмацыренов 2017: 140] Также он отмечает Интернет-сообщества, в которых «формируются новые религиозные и квазирелигиозные представления» [Бадмацыренов 2017: 142]. Здесь, возможно, также подошла бы концепция «Двух буддизмов», возможно, с какими-то уточнениями.

\section{Заключение}

Очевидно, что ни один из существующих на данный момент подходов к категоризации буддистов-мирян нельзя назвать исчерпывающим и лишенным недостатков. Это объясняется не столько несовершенством концепций, сколько тем, что формы существования буддизма в современном мире отличаются крайним многообразием. Невозможно одинаково точно классифицировать разные группы буддистов-мирян, используя какую-то одну концепцию. Вместе с тем стоить отметить, что современным исследователям все же удается вырабатывать более тонкие инструменты для фиксации и описания новых, прежде не охваченных групп буддистов-мирян (например, сочувствующие).

В отечественной историографии изучение буддистов-мирян только начинает развиваться как отдельное направление, поэтому в этой области теоретические наработки российских исследователей пока не так заметны. Необходимость в концептуальной разработке российского материала очевидна, интересно посмотреть, будут ли описанные выше подходы работать при анализе российских буддистов, или же потребуется их коррекция, а может быть понадобятся и новые теории.

\section{Благодарности}

Исследование выполнено при финансовой поддержке РФФИ в рамках научно-исследовательского проекта №17-21-03004 («Миряне и ламы: буддийские идеи и практики в трансформирующихся обществах России и Монголии»).

\section{ЛИТЕРАТУРA / REFERENCES}

Бадмацыренов 2017 - Бадмацыренов Т. Б. Религиозные практики в структуре культовой системы буддизма современной Бурятии // Власть. 2017. № 1. С. 139-144. [Badmatsyrenov T. B. Religious practices in the Buddhist cult system in contemporary Buryatia. Vlast'. 2017. No. 1. Pp. 139-144. (In Rus.)]

Жамбалова 2014 - Жамбалова С. Г. Народный буддизм и сангарил у бурят // Гуманитарный вектор. 2014. № 2 (38). Культурология. С. 116-125. [Zhambalova S. G. Popular Buddhism and Sangaril Ritual of Buryats. 
Gumanitarnyi vektor. 2014. No. 2 (38). Culturology. Pp. 116-125. (In Rus.)]

Жамбалова 2011 - Жамбалова С. Г. О народном буддизме в современной Бурятии // Гуманитарный вектор. 2011. № 2 (26). С. 87-93. [Zhambalova S. G. About popular Buddhism in present-day Buryatia. Gumanitarnyi vektor. 2011. No. 2 (26). Pp. 87-93. (In Rus.)]

Научно-практические конференции - Научно-практические конференции [электронный ресурс] // URL: http://www.buddhism.ru/ mprojects/nauchno-prakticheskie-konferentsii/ (дата обращения: 12.05.2018). [Nauchnoprakticheskie konferentsii [Research and practice conferences]. An Internet resource: see hyperlink above (accessed: 12 May 2018). (In Rus.)]

Островская 2016 - Островская Е. А. Буддийские общины Санкт-Петербурга. СПб. Алетейя, 2016. 198 с. [Ostrovskaya Е. A. Buddiyskie obschiny Sankt-Peterburga [Buddhist communities of St. Petersburg]. St. Petersburg: Aleteya, 2016. 198 p. (In Rus.)]

Шатравский 2018 - Шатравский С. И. К проблеме классификации общин буддистовконвертитов // Мониторинг общественного мнения: Экономические и социальные перемены. 2018. № 2. C. 141-164. [Shatravsky S. I. On the classification of the Buddhist convert communities. Monitoring obschestvennogo mneniya: ehkonomicheskie $i$ sotsialnye peremeny. 2018. No. 2. Pp. 141-164. (In Rus.)] Abrahms-Kavunenko 2012 - AbrahmsKavunenko, Saskia. Religious 'Revival' after Socialism? Eclecticism and Globalisation amongst Lay Buddhists in Ulaanbaatar. Inner Asia. No. 14 (2). 2012. Pp. 279-297. (In Eng.)

Elverskog 2006 - Elverskog, Johan. Two Buddhisms in Contemporary Mongolia. Contemporary Buddhism. 2006. Vol. 7. No. 1. Pp. 29-46. (In Eng.)
Freiberger 2004 - Freiberger, Oliver. The Buddhist Canon and The Canon Of Buddhist Studies. Journal of the International Association of Buddhist Studies. Vol. 27. No. 2. 2004. Pp. 261-283. (In Eng.)

Hardacre 2004 - Hardacre, Helen. Laity. Encyclopedia of Buddhism. Robert E. Buswell (ed.). 2004. 1000 p. (In Eng.)

Kaplan 2017 - Kaplan, Uri. Assembling the Laity: Standardizing Lay Buddhist Affiliation via Education in Contemporary Korea. Journal of Korean Studies. Vol. 22. No. 1. Spring 2017. Pp. 143-176. (In Eng.)

Numrich 2008 - Numrich, P. North American Buddhists in Social Context. Leiden, BRILL, 2008. 250 p. (In Eng.)

Numrich 2003 - Numrich, Paul David. Two Buddhisms Further Considered. Contemporary Buddhism. 2003. Vol. 4. No. 1. Pp. 55-78. (In Eng.)

Prebish 1979 - Prebish, Charles. American Buddhism. North Scituate, MA: Duxbury Press, 1979. 250 p. (In Eng.)

Scherer 2014 - Scherer, Burkhard. Conversion, Devotion, and (Trans-)Mission. Understanding Ole Nydahl. Buddhists: Understanding Buddhism Through the Lives of Practitioners. $1^{\text {st }}$ edition. Todd Lewis (ed.). Hoboken, NJ: John Wiley \& Sons, 2014. 352 p. (In Eng.)

Scherer 2009 - Scherer, Burkhard. Interpreting the Diamond Way: Contemporary Convert Buddhism in Transition. Journal of Global Buddhism. No. 10. 2009. Pp. 17-48. (In Eng.)

Storhoff, Whalen-Bridge 2010 - Storhoff, Gary; Whalen-Bridge, John. American Buddhism as a Way of Life. Albany: State University of New York Press, 2010. 229 p. (In Eng.)

Westward Dharma 2002 - Westward Dharma. Buddhism Beyond Asia. Charles S. Prebish, Martin Baumann (eds.). Berkeley: University of California Press, 2002. 388 p. (In Eng.) 
UDC 294.321

\title{
Lay Buddhists: \\ Classification Problems and Research Approaches
}

Rustam T. Sabirov ${ }^{1}$

${ }^{1}$ Ph.D. in History (Cand. of Historical Sc.), Associate Professor, Institute for Asian and African Studies, Lomonosov Moscow State University (11/1, Mokhovaya St., Moscow, 125009, Russian Federation). ORCID: 0000-0003-4660-098 E-mail: tabarzin@gmail.com

\begin{abstract}
In the $20^{\text {th }}$ century, lay Buddhists began to play a far more important role in religious processes both in the West and in Asian countries. Attempts to categorize western Buddhists have shown that the standard division into monks and laity does not work anymore. Going beyond Asia and adapting to new socio-political, economic and cultural conditions, Buddhism has transformed and inevitably taken new forms. The approaches and criteria developed over many years of studying Buddhism in Asia do not describe the whole variety of forms of involvement of western followers. And in the countries of Asia, modernization, secularization and globalization resulted in significant transformations of Buddhist communities.

The article shows the main approaches to classify modern Buddhists and the theoretical problems faced by scholars. One of them is the fact that the religious affiliation of the researchers themselves can often influence their conclusions about the authenticity of certain Buddhist groups and the assessment of their activities. The most vivid example is the interpretation of activities by followers of Ole Nydahl. Reference to these groups as 'neo-Buddhist' provides no insight into their nature. Currently, the problem of lay Buddhists' classification is best developed on the North American materials. Scholars criticize the normative approach according to which religious identity is something integral and fixed. On the contrary, the identity of modern western Buddhists results from a variety of factors. Formal criteria - refuge taking, visiting of temples, etc. — do not reveal the diversity of followers of Buddhism. Western researchers offer to pay attention to a large group of people who do not formally belong to Buddhism but show interest in it - the latter called 'sympathizers'. They have been an important part of the history of Buddhism since about the late $19^{\text {th }}$ century. Scholars recognize the valid and important the easiest criterion — Buddhist is the one who says 'I am a Buddhist'.

The main trends in the transformation of Buddhist practice in the West are the lack of a clear borderline between lay people and 'professional Buddhists', lack of common authorities, decline of monasticism, egalitarianism, the increase in the role of women, active participation in public life, often emphases on the psychological rather than religious nature of Buddhist practice. Some researchers suggest it can well be identified as a new Buddhism — a qualitatively different phenomenon emerging in the aftermath of adapting Buddhism to postmodern society. Others wonder whether western Buddhism can actually be viewed as a religion.

Many scholars criticize the popular concept of the 'two Buddhisms' that distinguishes between ethnic Buddhists (immigrants) and converts ('white Buddhists'). The use of this concept in the long term shall definitely give rise to further problems: How to classify the descendants of immigrants and converts? Alternatively, some scholars suggest traditionalist and modernist Buddhism(-s) be considered. However, this approach does takes no account of the fact not all converts follow modernist Buddhism, and not all immigrants are traditionalists.

The problem of Buddhists' classification is relevant not only in the western context. Examining a number of cases from Mongolia and Buryatia, the article illustrates similar tension can also be traced in those regions, and it is difficult enough to identify clear categories of believers.
\end{abstract}

Keywords: Buddhism, lay Buddhists, laity, Buddhism in the West, Buddhist studies 